\title{
AUDIOVISUAL TRANSLATION AS MEANS FOR INTERCULTURAL COMPETENCE DEVELOPMENT IN TRANSLATOR TRAINING
}

\author{
Jolita Horbacauskiene, Gintas Bartaskevicius \\ Kaunas University of Technology, Lithuania \\ E-Mail: jolita.horbacauskiene@ktu.lt, gintas.barte@gmail.com
}

\begin{abstract}
Translation is becoming one of the most effective means in intercultural communication. Translator training programs are considered to be successful only when they provide background to develop and foster intercultural competence among others. The paper presents the discussion on the challenges and possibilities of audiovisual translation in subtitled and dubbed modes as well as the results of the analysis of spoken language elements translation.
\end{abstract}

Key words: translator training, intercultural competence, audiovisual translation, dubbing, voice over

\section{INTRODUCTION}

Translator training has been under transformation for the last twenty years. The structural and methodological changes have to be implemented taking into account the requirements in Bologna Declaration, the European Master's in Translation network framework for translator and translation competence (EMT, 2009; 2017) and the European Quality Standard for Translation Services 17100 (2015), as well as currently evolving approach of sustainable teaching and learning in institutions of higher education. Student-centred teaching and learning methodologies are considered to be prerequisites for a present-day curriculum. When talking about particular competences graduates should acquire before entering the professional market, the cultural and intercultural competence, among others, in translator training has been formalized for many years now. In the last twenty years it has become one of the main competences the translator training curricula should develop due to increasing globalization impacts, emigration and immigration issues. Together with different types of translation and interpreting the importance of audiovisual translation (AVT) has also raised as the variety of AVT products and their prevalence and accessibility has expanded enormously. This paper discusses the challenges and possibilities of AVT in subtitled and dubbed modes as well as presents the results of the analysis of spoken language elements translation in subtitled and dubbed versions of the same AVT product.

\section{Challenges of Audiovisual Translation}

Translation, as noted by Walravens (2017) is a cross-cultural activity, which happens on "the borderlines between cultures and attempts to transcend the border that separates

Submitted March $3^{\text {rd }}, 2019$, accepted for publication April $15^{\text {th }}, 2019$ 
two (or more) peoples, communities or individuals" (p. 39). In order to transfer the meaning translators "should be made aware that they are cultural mediators and that mediation between cultures requires careful consideration" (ibid, p. 49). Eyckmans notes (2017) that the mediating role of a translator requires deep understanding of source text and culture as well as target text and culture in order to "transpose a particular text that was written to perform a function in the source language and culture into a new form in order to perform a function in the target language and culture "(p. 209). Fantini (2009) suggests that the ability to communicate or transfer the differences in languages and cultures may be termed as cross-cultural adaptation, cross cultural awareness, intercultural sensitivity, global competence, transcultural communication and many more. In translation studies, cultural knowledge and cultural skills, together with an advanced language competence in source and target languages, form a significant part of translation competence not only in the works of translation scholars but also on the level of formal requirements (EMT (2009, 2017); ISO 1700 (2015)).

Audiovisual text, according to Patou-Patucchi (2013), is a type of a text that no longer consists only of writing. It includes graphics, symbols, emotions, etc. Stockinger (2012) argues that the analysis of an audiovisual text consists of "a set of concrete activities" in order to expand knowledge about the specific item a researcher might not know, and "a process of compiling and distributing a body of knowledge heritage" (p. 8a). Thus, a translator, during the process of translation has to find every object that might have a specific relation with the source text meaning. The verbal and non-verbal cohesion becomes even more important in audiovisual translation as it requires accurate and correct transformation into the target text and culture in order to create an accurate image of a particular situation. Satkauskaite et al. (2015) argue "that translators of audiovisual products should take all the things into consideration in order to make a product coherent to a target audience in semantics and iconographic"(p. 27).

Bartrina (2004) describes the audiovisual text as an object where the text is everything that is being received through visual and acoustic channels, even music, movements. The author raises an issue that such audiovisual translation needs a specific theory to "discard the general models for the field outlined within the theory of translation." (p. 157). Thus, the cultural competence of a translator becomes of a vital importance when the translation or rendering of the audiovisual text is performed. Many scholars (Gottlieb (1998, 2005), Bartolome and Cabrera (2005), Franco, Matamala \& Orero (2010), Chaume (2013), Matkivska (2014)) present various typologies of audiovisual products' translation, including dubbing, partial dubbing, voice-over, free commentary, simultaneous interpreting, simultaneous translation, simultaneous interpreting, surtitling, conventional subtitling, intertitling, audio description for the blind and the partially sighted, audiosubtitling, and fandubbing included into two main groups of revoicing and subtitling. At the same time, multimodality of the text is highlighted as one of the most significant elements when translating the audiovisual product as the translator has to not only transfer what was said but also to give "analysis and interpret events" (Franco, Matamala \& Orero, 2010, p. 15). Jüngst (2013) compares the Internet environment for online broadcasted speeches interpreting using voice-over audiovisual translation strategy to simultaneous interpreting. In simultaneous interpreting the constrains of technical, lexical or semantical parameters are not taken into consideration in the process of translation, while in voiced over versions of the text, the audience usually listens to a summary of the original text. 
One more important issue the translator should pay attention to when translating for dubbing or subtitling is localization. If the translator successfully overcomes the challenges of localization, the audiovisual product may be more popular in the target audience then in the source locale. Pym (2001) notes that localisation is a process of taking a product and making it appropriate not only linguistically but also culturally to the target locale where it is going to be used. Esselink (2000) defines localisation as translation and adaptation of a product, while Maumeviciene (2011) argues that it also may be considered as an act of communication, which helps to communicate between different cultures. A film translation is a completely different genre if compared to translation of written text as it includes many channels that have to be taken into account. All these channels have to be transferred, adapted during the film localisation process in order to make the particular audiovisual product successful in target audiences (Liubiniene, Beniusyte 2014). Satkauskaite et al. (2015) note the importance of visual and verbal cohesion, violations of which may create inaccurate image of a situation and the audience might be disturbed. Following Chaume (2013), they argue that cohesion between a plot and dialogue, i.e. between a word and an image, is one of the translated audiovisual text quality standards allowing the translator to retain semantic and iconographic cohesion (Satkauskaite et al., 2015, p. 27). Elements of formulaic language (expressional collocations, idioms, phraseological units, cultural symbols, metaphors, culture specific items, etc.) also called cultural identification marks help to make the audiovisual product closer to a target audience (Shariati et al., 2013) if the translation is well done. The successful transference of cultural marks from one language to another is a challenge for a translator.

One more challenging issue when translating audiovisual product is the translation of humour. Berger (1998) proposes a classification of humour that falls into the following categories: language where humour is verbal (e.g. insults, irony, sarcasm, satire, etc.); logic where humour is ideational (mistakes, ignorance, disappointment, repetition, etc.); identifying where humour is described as existential (parody, caricature, mimicry, etc.); and action where it is physical and nonverbal (speed, time, slapstick, chase). Humour translation/adaptation in a movie requires that translator has deep knowledge in both cultures and languages in order to recognize a joke, an anecdote that might be difficult due to cultural differences, maybe political or country-specific events, etc. Chiaro (2013) as one of the biggest problems mentions "untranslatability" in the sense that it is hard to achieve an "adequate degree of equivalence" (p. 8). Lepre (2015) argues that if one culture is not far away from another, thus humour is well understood even cross-culturally, contrary translators face more problems if cultures are far from each other, issues rise due "to puns, culturemes and sociolinguistics" (p. 92). Translators have to find a solution to keep a relation between verbal and visual elements related within a joke (Mudriczki, 2014, p. 53). Mudriczki (2014) suggests humour translation strategies that can help a translator to cope with this issue: smooth humour transfer, it may be used when a translator does not need to make any modifications in order to retain the meaning; visual clue constrained humour transfer, when verbal elements are being changed because visual features of the source text cannot be changed; and, adaptive humour transfer, when some humour elements disappear but new element are added. Successful identification of cultural marks as well as appropriate choice of translation strategies may be the key elements when aiming at best quality standard translation.

During the act of communication, language may vary at lexical, syntactic and/or phonological levels as well as different dialects, accents and registers. Depending on the type of movie, instances of language may be classified into formal or informal standard. As 
Minutella (2014) notes, sometimes it is quite difficult to determine whether a word, a collocation, a sentence is considered to be formal or informal, if nonstandard words are used. Constrains of geographical, temporal, social, standard/non-standard or idiolects as well as several registers may be used interchangeably and as Bonsignori (2013) argues the determination of the precise meaning depends on a particular situational context, relationship between two communicating parts, social roles during the conversation, and communicative intentions. Usage of spoken language represents informal style of communication and speakers do not have to pay a lot attention to a sentence structure, vocabulary, they feel less bounded. Dabrowska (2013) provides five formality levels of stylistic variations: intimate, used among people who know each other very closely; casual, used in communication with friends; consultative or neutral, used to talk with strangers; formal, used in official situations; and, frozen or pre-described code of conduct, e.g. in church, court. Quaglio (2009) claims that expletives or taboo terms are used only in informal speaking and they might be "associated with emotionally-loaded language" (p. 101), while Murphy (2010) defines taboo language as dependent on age and life stage or social class. Speakers during the informal act of communication are not afraid to show their emotions, they can clearly express their attitude not only saying a simple word, but also varying their voice tone, intonation, showing gestures, facial expressions, etc. Speakers may employ a variety of linguistic features, i.e. intensifiers (so), discourse makers (wow), expletives (damn), lexical bundles (I can't believe + complements), emphatic do, and slang terms (freak out) in order to express their emotions (Quaglio 2009). Spoken language features have to be transferred from the source text to the target text/audience in order to not only understand the main meaning but also to transfer emotion of the source text. As it was mentioned before, some of the features of spoken language appear only due to emotional reasons. Thus, thus has to be taken into consideration. In order to transfer not only the meaning but also the emotion, a translator has to take into account some aspects of sociolinguistics. Mesthrie et al. (2009) argue that language is indexical of many factors including social class, status, gender, age group or region of origin which could be helpful in social identification of a speaker. The translator has to find out what emotional weight a particular word or phrase has in a specific context and his/her ability to identify sociolinguistic aspects may be useful in determining the meaning, emotion of a word and transferring it to the target language.

\section{TRANSLATION OF SPOKEN LANGUAGE ELEMENTS IN DUBBED AND SUBTITLED VERSIONS}

The study was conducted during the translation practice classes with third year students of translator training study program. Their main aim was to identify the instances of spoken language in the source text and compare with the target text as well as present translation analysis indicating the translation procedure applied and their own explanations. The examples ( $\mathrm{n}$ 282) were classified according to the spoken language typology defined by Quaglio (2009). Subtitled translations of these instances were analysed following Gottlieb's subtitling strategies as they are used in many similar studies as a background of the analysis of subtitles, namely: explanation, usually used to explain cultural specific items that are not recognized in the target culture; paraphrase, used for phraseological units that cannot be transferred to the target language in the same syntactic way; transfer, applied for a complete and accurate translation; imitation, for keeping names of people and places in the same 
form as in the source text; transcription, used for terms that are not known even in the source language, e. g. "the use of a third language or nonsense language"; dislocation, used for special effects, e.g. when a song or other sounds are even more important than the content, i.e. the effect has to be translated; condensation or shortening of text; decimation or extreme form of condensation. It happens when speakers talk very fast and even important information are omitted; deletion or complete omission of text elements; resignation, when there is no translation solution and there is no way to keep the same meaning.

Dubbed version of the instances of spoken language used in the film is analysed following Pettit's (2009) translation strategies for cultural transfer, namely: omission, when the cultural component is not transferred to the target product; literal translation, the target text translation matches the one used in the sources text very closely; borrowing, the same terms used in the original text are transferred to the target text; equivalence, the meaning and the function of the translated term is the same in both, the source and the target cultures; adaptation, when the translation seeks for the similar connotation; replacement of the cultural term, when gestures of visual clue are used on the screen; generalization, when original text is being neutralized; and, explication, a paraphrase is used for explanation of the cultural item. The results of the analysis present the discussion of the similarities, differences, advantages, and disadvantages of the dubbed and the subtitled versions of the Despicable Me 2 (92 min.).

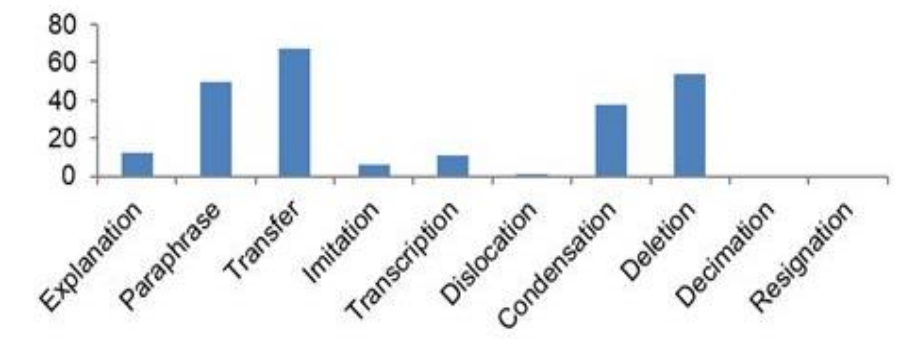

Fig. 1 Translation Strategies of Spoken Language Elements in Subtitled Version

Gottlieb (2004) argues that "subtitling is as an instrument to improve reading skills, boost source language skills, in a simple and cheap way facilitate international program exchange, and show the English as dominant language" (p. 87). Nevertheless, there is an opposing opinion stating that the audience might just read subtitles and not listen to the original foreign dialogue, in this case neither the source language skills, nor the target language skills are improved (Denan, 2004). The process of subtitling has very strict technical requirements that should be followed while translating the source text. Due to this reason there were 54 elements deleted and condensation strategy had been used for 38 elements. In this case, fewer characters had to be written per subtitle in order to keep to subtitle reading time constrain. Translation strategy of condensation was used mostly for repetitions. The most frequently used strategy was transfer, which could be explained by the fact that the translator retained a close relation between the source and the target texts when translating spoken language elements, i.e. slang, greetings and leave-takings, vocatives and humour and other elements which show cultural identity. Paraphrase translation strategy was also used frequently due to the technical requirements of subtitles as well as grammatical, syntactic or semantic differences in source and target languages. 


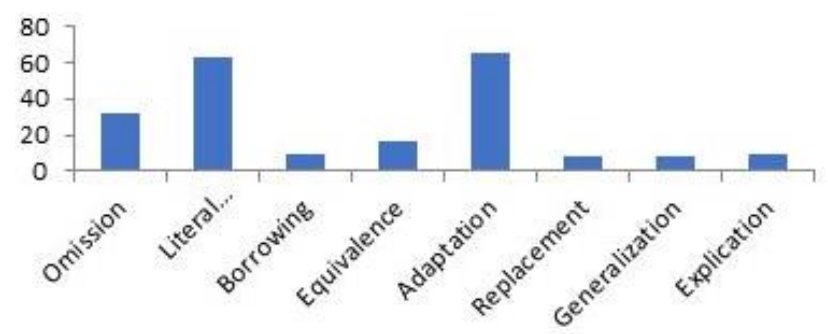

Fig. 2 Translation Strategies of Spoken Language Elements in Dubbed Version

The results of the analysis revealed that the dubbed version may be considered to be more localized to the Lithuanian audience than the subtitled one as the translation strategy of adaptation was used most frequently to dub the elements of spoken language (66 times). This strategy has been used to transfer humour elements, repetitions, discourse particles and slang. These are the elements that help to create the impression of reality. Slang and humour are the most frequent elements used to reveal cultural identity. Thus, the target audience might get the illusion that the film is actually made by Lithuanians due to the culture-specific elements used. It should be noted that translator's choice to use literal translation (63 times) so often might lead to some misunderstandings due to cultural differences. On the other hand, this might be helpful to the audience to learn foreign language due to the exact translation of the source text. Both languages have sociolinguistic differences and in many cases, the elements have to be changed in order to transfer clear meaning that would not raise the question what is being told by saying one or another element. In the dubbed version extralinguistic elements were more taken into consideration than verbal elements than in the subtitled version. Therefore, this might be the reason why adaptation is the most frequently used translation strategy in dubbing.

The Mexican culture elements and Spanish language were usually used to identify origin of some characters. In the dubbed and in the subtitled versions, this identity was retained. In the subtitled version of the film, the transcription translation strategy was used for this purpose (11 times). Therefore, the audience could clearly detect the culture. The Spanish terms were retained in the dubbed version as well. In the cases, the Spanish vocative was used as a vocative, it had been simplified in the translated version.

Explanation (12 times) in the subtitled version had only been used to translate slang elements and idioms. These are cultural-specific items and might not be understood in other countries. On the other hand, it was not the most frequently used translation strategy to translate slang, but the most popular to translate idioms. The same happened with the translation of idioms in the dubbed version and it could be argued that it lowered the level of expressivity in the target text. One more thing to notice is that some elements were translated completely differently in the subtitled and dubbed versions. It might indicate that the different translations were not compared, but in order to increase the overall quality of translations it could be useful to do.

The analysis also exposes the similarities and differences of sociolinguistic origin of source and target languages. They may be well illustrated by the following example of transfer of expletives in the subtitled version: 
Gru: The twenty-one fart gun salute! - 21 bezdalo saliutas! [20:40]

Gru: Yes... they stink. - Teisingai. Jie dvokia. [1:09:25] The first one is expletive because fart is a term used in non-formal lexis. In the Lithuanian subtitled version it is translated using condensation / paraphrase / transfer strategy. The provided translation solution does not transfer the exact meaning. Fart gun is translated as bezdalo (back translation - fart, a noun in genitive case). If there were no video, only text, such translation might be understood as twenty one people standing and farting, but in the source text and in the video minions stand with guns and shoot. Thus, the deletion of gun may raise some misunderstanding. Salute is transfered as saliutas. The word saliutas is not used in such situations in the target language. Despite the fact, that saliutas means to honour somebody by shooting a canon, etc., in Lithuanian it is usually used to name fireworks. A more reasonable term would be salve (back translation round, e. g. to fire 21 round). Therefore, 21 bezdalo saliutas if there were no video might be understood as twenty one person standing and shooting fart fireworks. This choice of words in the target text may raise some understanding issues as the noun saliutas is normally used in a different context.

The next example is interesting because of the context this sentence was used: Margo was upset seeing Antonio dancing with another girl and said Gru she hated boys. Gru's answer was Yes... they stink. The translator used a transfer or literal translation strategy Teisingai. Jie dvokia. The translation itself is good but does not transfer the real meaning of the sentence. Without the video and the context it would look as Antonio did not have a shower for days and is stinky. The translation does not show the exact meaning that Gru is angry on Antonio and shows antipathy, distaste and anger. Thus, a transfer strategy is not the best option in this case. With reference to the technical requirements of subtitles, this particular choice of words could be based on the fact that the translator noticed that Gru holds the word Yes and chose a longer translation version. Yes instead of a simple Taip (back translation yes) was translated as Teisingai (back translation is Correct) Both have the same meaning, but the seconds helps to read the subtitle at the moment when the actual words in the source text are said. In the dubbed version the translation is Taip. Jie niekšai (back translation yes, they are scoundrels). The provided translation solution is a more suitable option than to choose literal translation. The Lithuanian translation carries even bigger emotional background than the one in the source text. Synchronically, the translation is longer, but the Lithuanian speaker talks faster and manages to start and end the sentence at the exact time.

Gru: And don't go nuts with the sprinkles! - Ir neišdykaukite su pabarstukais! [24:22] The English collocation don't go nuts with is very wide in meaning which may vary from very intimate to very casual. It is always used in spoken language and is considered to be informal. But the exact meaning depends on the context a lot. Therefore, if context or extralinguistic elements would be different, this collocation might be classified as taboo or expletive. In this specific context, the collocation means not to do what minions want. Minions become out of control very fast in any situation. The subtitle in Lithuanian is neišdykaukite (back translation do not romp around). The meaning of the word in the target language differs from the English collocation because the English one has a specific hidden meaning which is difficult to reveal from individual components, and the meaning of the Lithuanian one is very clear. The Lithuanian translation is different in syntactic form, but transfers the meaning which is told in the source text.

The comparison of the translations of two different audiovisual modes reveals that the target text tends to be more neutralised then the source text. Very strict language regulations 
may be the reason for translators' choices to make the target text less eloquent than the source text. Nevertheless, the translators' competences and knowledge in intercultural communication are of primarily importance when translating the audiovisual products in various modes. The correct transference of text together with extralinguistic features helps to create the impression of reality in and for the target audience.

\section{FinAL REMARKS}

Today translation may be considered a very important tool for intercultural communication. The translator when preparing the translated text for the target audience has to look at it not only from the perspective of linguistics but also from the different cultures. This is especially applicable in translating for audiovisual mode, where the visual images may be more valuable than the words.

The results of the study present the following insights: firstly, the elements of spoken language were translated to retain the relation between the source and target languages; secondly, the majority of discourse particles and repetitions were deleted or condensed due to the strict technical requirements of subtitles, thus resulting in non-transferred emotional issues to the target text. At the same time, sometimes translators did not pay attention to some particular motions or intonations while these elements might be decisive in order to get the meaning correctly; thirdly, as the translation strategy of adaptation was the prevailing one in the dubbed version, all features of natural effect in the target culture were achieved, including the dialogues producing credible and true-to-life effect, lip synchronization was compiled; a balance avoiding overacting and underacting during the process of communication was achieved. Nevertheless, the language of the source text is more expressive than the subtitled and dubbed versions in the target language. Many slang terms were neutralized. Only the minority of them had the same function and emotional background. On the other hand, the elements of Mexican culture are retained in both subtitled and dubbed versions in the target language. The italics and Spanish words were used in the subtitles, and some Spanish words and the Spanish accent were heard in the dubbed version. The language of the subtitled version remained closer to the source text due to the frequent usage of transfer translation strategy, while the dubbed version was more adapted to the target culture while creating the impression of reality.

\section{REFERENCES}

Bartolomé, H. A. I.; Cabrera, G. M. (2005). New Trends in Audiovisual. Translation: The Latest Challenging Modes. Miscelánea 31, p. 89-103.

Bartrina, F. (2004). The challenge of research in audiovisual translation. In Pilar, O. (ed.) Topics in Audiovisual Translation, Amsterdam and Philadelphia: John Benjamins Publishing Company. pp. 157-168.

Berger, A. A. (1998). An Anatomy of Humor. New Brunswick, NJ: Transaction

Bonsignori, V. (2013). English Tags. Newcastle-upon-Tyne: Cambridge Scholars Publishing. Retrieved from https://ebookcentral.proquest.com/lib/ktu-ebooks/detail.action?docID= 1731955.

Chaume, F. (2013). The turn of audiovisual translation: New audiences and new technologies. Translation Spaces, Vol. 2, p.105-123. 
Chiaro, D. (2013). Translation, Humour and Literature. London: Continuum International Publishing Group.

Dabrowska, M. (2013). Variation in Language. Frankfurt am Main: Peter Lang GmbH, Internationaler Verlag der Wissenschaften. Retrieved from https://ebookcentral.proquest. com/lib/ktu-ebooks/detail.action?docID=1632287

Denan, M. (2004). Captioning and Subtitling: Undervalued Language Learning Strategies. Meta: Translators' Journal, vol. 49, No. 1, p. 67-77.

EMT expert group. (2009). Competences for professional translators and experts in multilingual and multimedia communication. Available at <https://ec.europa.eu/info/sites/ info/files/emt_competences_translators_en.pdf > (accessed 26 January 2019).

EMT Competence Framework (2017). Available at: https://ec.europa.eu/info/sites/info/ files/emt_competence_fwk_2017_en_web.pdf (accessed 26 January 2019).

Esselink, B. (2000). Practical Guide to Localization. Philadelphia: John Benjamins Publishing Company.

Eyckmans, J. (2017). Cultural Competence in Translation Studies and its Assessment. In (eds.) Julie Deconinck, Philippe Humblé, Arvi Sepp, Hélène Stengers Towards Transcultural Awareness in Translation Pedagogy. LIT Verlag GMBH\&Co. KG Wien. p.209-230.

Fantini, A. E. (2009). Assessing Intercultural Competence. Issues and Tools. In Darla K. Deardorff (ed) The Sage Handbook of Intercultural Competence. London: Sage Publications, p. 457-476.

Franco, E.; Matamala, A.; Orero, P. (2013). Voice-over Translation. Bern: Peter Lang AG, Internationaler Verlag der Wissenschaften.

Jüngst, H. E. (2013). The Potential of Integrating Dactivities in the Translation Classroom. Trans. Revista de traductologia. Nr. 17 pp. 103-114.

ISO 17100. (2015). Translation Services-Requirements for Translation Services. Technical Committee ISO/TC37, 2015.

Gottlieb, H. (2004). Language-political implications of subtitling. In Pilar, O. (ed.) Topics in Audiovisual Translation, Amsterdam and Philadelphia: John Benjamins Publishing House, pp. 83-100.

Gottlieb, H. (2005). Multidmensional Semantics Turned Semiotics, MuTra 2005 - Challenges of Multidimensional Translation: Conference Proceedings, pp. 1-29. Available at: http://www.euroconferences.info/proceedings/2005_Proceedings/2005_Gottlieb_Henrik.p df. (accessed 28 December 2018).

Gottlieb, H., (1998). Subtitling. In Baker, M. (ed.), Routledge Encyclopedia of Translation Studies, London and New York: Routledge, pp. 244- 248.

Lepre, O. (2015). Cultural References in Fansubs: When Translating is a Job for Amateurs. In Perego, E., Bruti, S. Studies in Language and Translation: Subtitling Today: Shapes and Their Meanings (1), pp. 77-96.

Maumeviciene, D. (2011). Lokalizacija kaip komunikacijos aktas. Vertimo studijos, vol. 4, p. 95-106.

Matkivska, N. (2014). Audiovisual Translation: Conception, Types, Character's Speech and Translation Strategies Applied. Kalbu studijos. Nr. 25, 38-44.

Mesthrie, R.; Swann, J.; Deumert, A.; leap, W. (2009). Introducing Sociolinguistics. Edinburgh: Edinburgh University Press. Retrieved from https://ebookcentral.proquest. com/lib/ktu-ebooks/detail.action?docID=448743, (accessed 12 December 2018) 
Minutella, V. (2014). Translating verbally expressed humour in dubbing and subtitling: the Italian version of Shrek. (eds.) In De Rosa. G. L.; De Laurentiis, F.B.A.; Perego, E. (2014). Translating Humour in Audiovisual Texts. Bern: Peter Lang AG, Internationaler Verlag der Wissenschaften, p. 67-89.

Mudriczki, J. (2014). Audiovisual humour transfer strategies in the Italian, German and Hungarian dubbed versions of Shrek the Halls. (eds.) In De Rosa. G. L.; De Laurentiis, F.B.A.; Perego, E. (2014). Translating Humour in Audiovisual Texts. Bern: Peter Lang AG, Internationaler Verlag der Wissenschaften. p. 51-65.

Murphy, B. (2010). Corpus and Sociolinguistics. Amsterdam: John Benjamins Publishing Company. Retrieved from https://ebookcentral.proquest.com/lib/ktu-ebooks/detail.action? docID $=623337$.

Liubiniene, V.; Beniusyte-Milasiene, S. (2014). What is the Successful Film Localization? The Case Study of Dub Localized Songs in Garfield Story. American International Journal of Social Science, 3(7), 100-106.

Patou-Patucchi, S. (2013). The viewer/learner of audiovisual language. In Buffagni,. C., Garzelli, B. Film Translation from East to West: Dubbing, Subtitling and Didactic Practice, CHE: Peter Lang AG pp. 21-27.

Pettit, Z. (2009) Connecting Cultures: Cultural Transfer in Subtitling and Dubbing, in Diaz Cintas, J. (ed.). New Trends in Audiovisual Translation. Bristol, Buffalo, Toronto: Multilingualism Matters. p. 47-61.

Pym, A. (2001). Localization and Linguistics. SLE conference, August 2001, pp. 1-14. Retrieved from http://usuaris.tinet.cat/apym/on-line/translation/loclinguistics.pdf

Quaglio, P. (2009). Television Dialogue. Amsterdam: John Benjamins Publishing Company. Retrieved from https://ebookcentral.proquest.com/lib/ktu-ebooks/detail.action?docID= 623198.

Satkauskaitè, D., Onskulytė, M., \& Arbaitienė, 1. (2015). Deiktinė referencija kaip personažo ìvaizdžio kūrimo priemonė dubliuotame animaciniame filme „Sniego laiškanešys“: lietuviškos, rusiškos Ir angliškos versijos palyginimas. Coactivity / Santalka, 23(1), p. 26-37.

Shariati, Z., Dabaghi, A. \& Amirian, Z. (2013). Strategies for dubbing of cultural differences: the case of „Due South”, Episode 65. Journal of Second and Multiple Language Acquisition-JSMULA. Vol. 1, Issue: 3. pp. 38-51.

Stockinger, P. (2012). Audiovisual Archieves: Digital Text and Discourse Analysis. London: John Willey \& Sons.

Walravens, J. (2017). Towards a Culture Based Paradigm for Translator Training. In (eds.) Julie Deconinck, Philippe Humblé, Arvi Sepp, Hélène Stengers Towards Transcultural Awareness in Translation Pedagogy. LIT Verlag GMBH\&Co. KG Wien. p.39-52. 